J. Perinat. Med.

12 (1984) 339

\title{
Ultrasonic patterns of a cardiac rhabdomyoma detected in utero
}

\author{
L. Di Lollo, R. Castellani, A. Maiorana*
}

Department of Echography and Echocardiography of the Clinic Citta' di Roma, Italy

* Department of Pediatrics, Hospital Fatebenefratelli, Isola Tiberina, Rome, Italy

\section{Introduction}

Ultrasound represents a noninvasive method to obtain detailed informations about the developing human fetus. Recently two-dimensional echocardiography has enabled one to perform a more accurate exploration of the structure and rhythm of the fetal heart and it provides a method to detect major cardiac malformations such as defects of atrioventricular septum, valvular atresia, truncus arteriosus, tetralogy of FALLOT and hypoplasia of the cardiac chambers [1,6]. This paper describes antenatal sonographic findings of a left ventricular tumor detected at the 30th week of pregnancy.

\section{Case report}

A 25-year-old healthy woman gravida 3, abortus I (third month of gestation) was admitted for the first time at the 21 th week of pregnancy to perform a routine echographic examination. The family history was non contributory and pregnancy had proceeded uneventfully until that time. Real-time examination demonstrated a singleton fetus with vertex presentation whose growth parameters were within the normal range. The equipment used was a KONTRON ROCHE Real-Time linear scanner (SUPERSCAN 50) with M-mode regulation. Since the pregnancy had proceeded without complications, a second sonographic control was performed at the 30th week. During the evaluation of the thoracic diameter, a dense mass of echoes measuring $2.2 \mathrm{~cm}$ was seen within the fetal heart (Fig. 1). This mass appeared to protrude into the left ventricular cavity in close relation to the septum, to be pedunculated and move in rhythmic synchron with the heart beat, during all echographic observations (Fig. 2). This image appeared constant in each scanning. After three weeks it showed unchanged sonographic features without modifying normal embryocardiac rhythm.

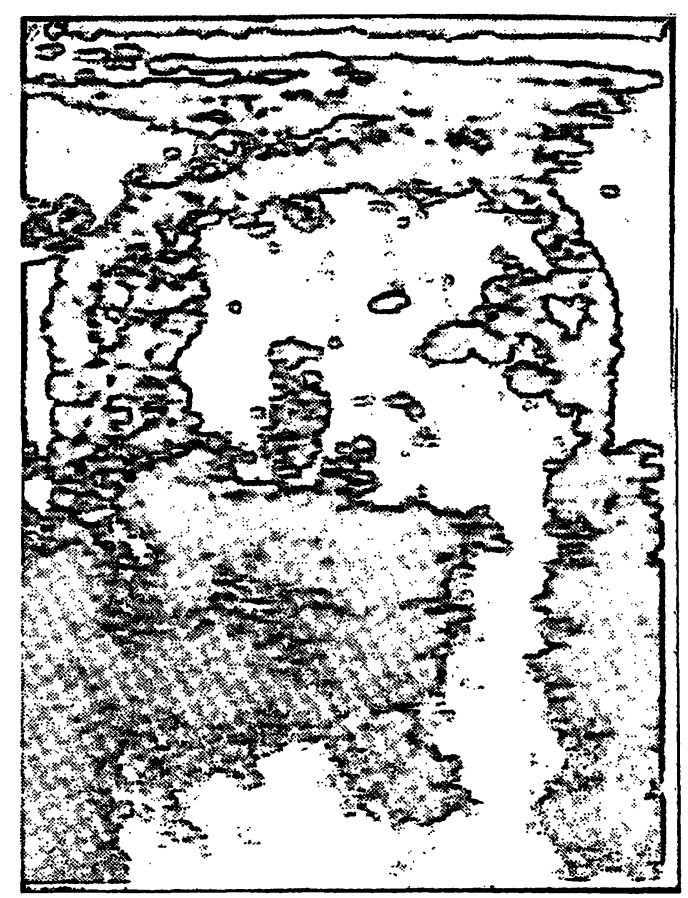

Fig. 1. Fetal heart's four chambers projection: the mass is in the left ventricular cavity closely related to the interventricular septum. 


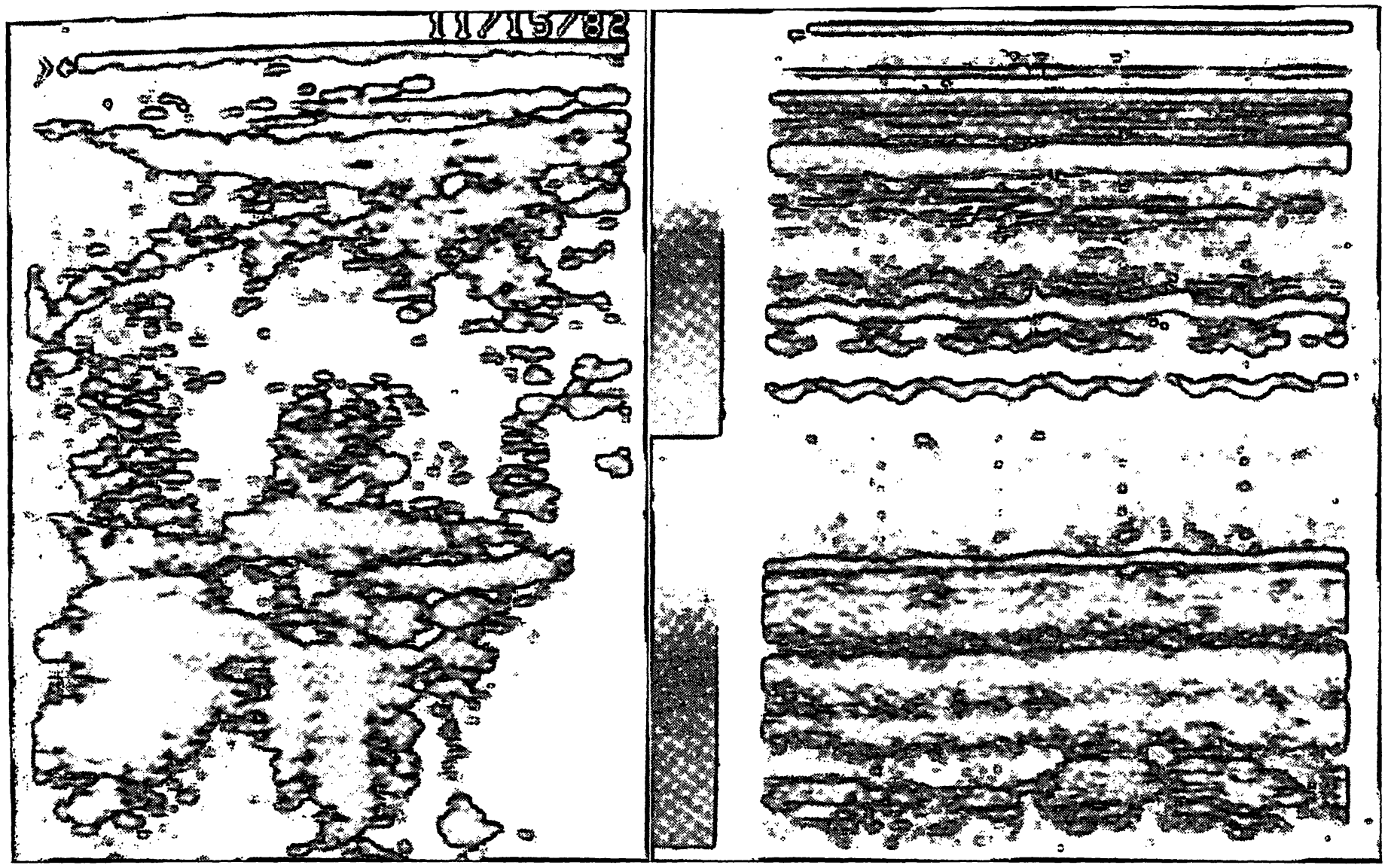

Fig. 2. M-mode and short axis bidimensional echoes of the mass.

The fetal development appeared above the superior limits. Since the obstetrical examination was normal and sonographic findings demonstrated no changes, pregnancy was normally continued until the 38th week when a male infant, weighing $3950 \mathrm{gm}$, was born by spontaneous delivery. Clinical examination showed a normal appearing infant with transient mild cyanosis. Auscultation revealed a grade $2 / 6$ ejection blowing murmur. No neurological abnormalities were noticed. In the first day of life the newborn infant had some cyanotic episodes but responded well to oxygen. Blood studies including acid-base balance were within normal range. Chest X-ray showed mild cardiomegaly with a normal pulmonary vasculature. The ECG showed an inconstant WPW. An echocardiogram confirmed the presence of a tumor mass occupying almost all of the left ventricular cavity, as had been detected previously in utero. As soon as possible, the baby was transferred to the Cardiovascular Surgery Center of the Bambino Gesú Hospital of Rome where a prompt removal of the mass $(2 \times 2 \times 3 \mathrm{~cm})$ was carried out in the second day of life. In addition two other smaller masses were discovered in the myocardium. Histological examinations of the tumor revealed a rhabdomyoma. The patients's subsequent clinical course showed continued improvement, with sufficient weight gain and normal psychomotor development EEG controls repeated performed demonstrated normal activity. Digoxin therapy was discontinued at nine months of age. At eleven months of age, computerized cranial tomography, performed after a febrile seizure episode, demonstrated the typical changes of tuberous sclerosis which represents the most recent finding in this infant.

\section{Comment}

Rhabdomyoma is the most frequent cardiac tumor among infant and children, and it coeists with tuberous sclerosis in more then $50 \%$ of cases [4]. 
The infants affected by rhabdomyoma clinically may present tachy-arrhythmias and they may demonstrate signs of low cardiac output. Removal of the hemodynamic obstruction is the primary surgical goal [4]. The routine use of two-dimensional echocardiography in this clinical setting has easily detected several cases of thabdomyoma in the newborn $[3,4,5,7,8]$. To date only one case of antenatal echographic examination has been published [2]. The authors stress the importance of an accurate sonographic evaluation of the cardiac image during pregnancy. In our case the antenatal observation of an intracardiac mass suggested the diagnostic probability of a tumor and permitted the planning of the immediate postnatal period with prompt surgical intervention.

\section{Summary}

Echography performed on a healthy woman at the 30 th week of an uneventful pregnancy demonstrated the presence of an intracardiac tumor protruding into the left ventricular cavity. In the early neonatal period a cardiovascular surgeon removed the mass which proved to be a

rhabdomyoma. The authors stress the importance of these echographic findings in formulating plans for the management of pregnancy, delivery and proper therapeutic intervention.

Keywords: Rhabdomyoma, two-dimensional echocardiography, ultrasound.

\section{Zusammenfassung}

Ultrasonographische Darstellung eines cardialen Rhabdomyoms in utero

Bei einer gesunden Frau wurde in der 30. Schwangerschaftswoche nach komplikationsloser Schwangerschaft ultrasonographisch ein fetaler, intracardialer Tumor, der in den linken Ventrikel hineinragte, nachgewiesen. Der Tumor, der einem Rhabdomyom zuzuordnen war, wurde in der frühen Neonatalperiode von einem Herz- und Gefäßchirurgen reseziert. Die Autoren betonen, daß solchen Ultraschallbefunden große Bedeutung zukommt, damit die Schwangerschaft und Geburt optimal geleitet werden können und eine sofortige therapeutische Intervention geplant werden kann.

Schlüsselwörter: Rhabdomyom, Ultraschall, zweidimensionale Echocardiographie.

\section{Résumé}

Aspect ultrasonore d'un rhabdomyome cardiaque dépiste in-utero

Une échographie réalisée chez une femme en bonne santé à la 30ème semaine d'une grossesse sans problème particulier a mis en évidence la présence d'une tumeur intracardiaque faisant protusion dans le ventricule gauche. Une intervention cardiovasculaire réalisée dans la période néonatale précoce a permis l'exérèse de la masse qui s'est révélée être un rhabdomyome. Les auteurs soulignent l'importance de ces données échographiques pour planifier la surveillance de la grossesse, de l'accouchement et pour proposer l'intervention thérapeu tique appropriée.

Mots-clés: Echocardiographie en 2 dimensions, rhabdomyome, ultrason.

\section{Bibliography}

[1] ALLAN, L.D., M. TYNAN, S. CAMPBELL et al.: Identification of congenital cardiac malformations by echocardiography in midtrimester fetus. Br. Heart J. 46 (1981) 358

[2] DE VORE, G. R., S. HAKIM, C. S. KLEINMAN et al.: The in utero diagnosis of an intraventricular septal cardiac rhabdomyoma by means of real-time directed, M-mode echocardiography. Am. J. Obstet. Gynecol 143 (1982) 967

[3] FITZPATRICK, P. G., N. C. NANDA, P. J. HARRIS et al.: Two-dimensional echocardiographic identifica- tion of multiple cardiac tumors in a newborn. Ultrasound Med. Biol. 8 (1982) 695

[4] GUTIERREZ DE LOMA, J., F. VILLAGRA, J. PEREZ DELEON et al.: Rhabdomyoma of the heart; surgical treatment. J. Cardiovasc. Surg. 23 (1982) 149

[5] HAUSDORF, G., S. SCHRODER, K. SIEGK et al.: Diagnose des kardialen Rhabdomyoms im Neugeborenenalter. Z. Kardiol. 72 (1983) 57

[6] KLEINMAN, C. S., J. C. HOBBINS, C. C. JAFFE et al.: Echocardiographic studies of the human fetus; pre- 
natal diagnosis of congenital heart disease and cardiac dysrhythmias. Pediatrics 65 (1980) 1059

[7] MILNER, S., J. A. ABRAMOWIT Z, S. E. LEVIN et al.: Rhobdomyoma of the heart in a newborn infant. Diagnosis by echocardiography. Br. Heart J. 44 (1980) 224

[8] REES, A. H., F. E. ELBL, K. W. MINHAS et al.: Echocardiographic evidence of left ventricular tumor in a neonate. Chest 73 (1978) 433
Received October 19, 1983, Accepted March 6, 1984.

Dr. ssa Luisa di Lollo

Via Friggeri 111

00136 Roma

Italia 